\section{AIR IN MEDICAL SCENARIOS}

Dürr Dental has launched the Duo Tandem Med compressor. The company were able to refine their existing membrane drying process to ensure it meets the standards required for implantology as well as maxillofacial surgery.

The membrane on the medical model guarantees that in continuous operation the unit will provide compressed air to medical quality. The residual water content, the pressure dew point and the particle and oil content all comply with the stipulations set out by the European Pharmacopeia

\section{BUILD STRONGER SMILES}

OSspray is pleased to announce the launch of its new Sylc therapeutic bioglass prophy powder. Sylc can clean teeth more efficiently than existing materials and rapidly combats sensitivity and promotes remineralisation of tooth surfaces with high levels of patient comfort, according to the company.

The product is a $100 \%$ calcium phosphosilicate bioglass material. Applied by a qualified dental professional using widely commercially available air

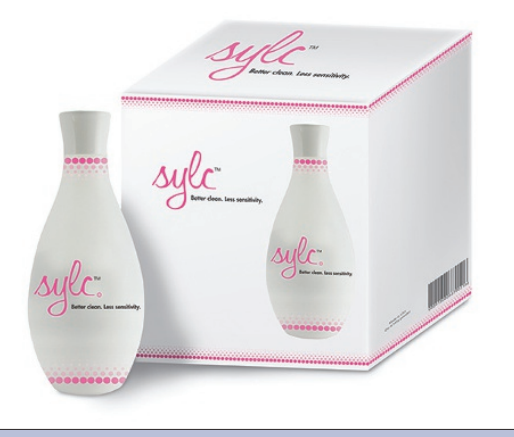

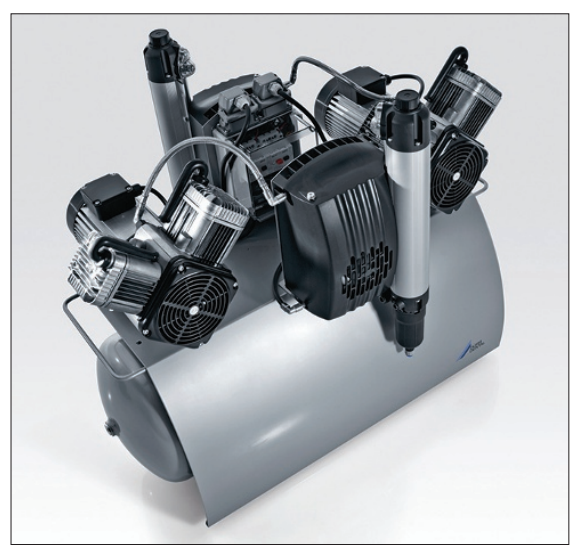

for the use of air in medical scenarios. Reader response number 63

polishing equipment, Sylc provides a wide range of clinical benefits including cleaning, polishing, desensitising, brightening, remineralising and antimicrobial properties.

The round bioglass particles can remove stain very effectively without damage to tooth structure and are gentle to soft tissue. The material is denser than traditionally prophy powders focusing the spray pattern accurately onto the tooth surface. Patient acceptance is further enhanced by the neutral, salt free taste. The particles are able to occlude dentine tubules immediately upon application and hence are able to reduce hypersensitivity rapidly.

Throughout the 24 hours post-treatment, Sylc continues to form hydroxycarbonate apatite crystals mimicking the development of natural tooth structure, and aiding the continuous reduction of sensitivity and strengthening the tooth surface.

Reader response number 64

\section{SMALL DIAMETER IMPLANTS}

Roxolid developed by Straumann is designed to meet the needs of dental implantologists and benefits from being 50\% stronger than pure titanium. Roxolid in conjunction with the SLActive surface has been used to create a range of small diameter implants and this combination of strength and osseointegration provides a wider choice of treatment options.

Designed to increase patients' acceptance of implant treatment, Roxolid implants offer greater confidence when placing small diameter implants as it requires less need for augmentation, is ideal for small interdental spaces/bone ridges and can be less traumatic for the patient.

Roxolid implants are available as a Straumann Standard, Standard Plus, Tapered Effect and Bone Level implant in $3.3 \mathrm{~mm}$ diameter neck.

Reader response number 65

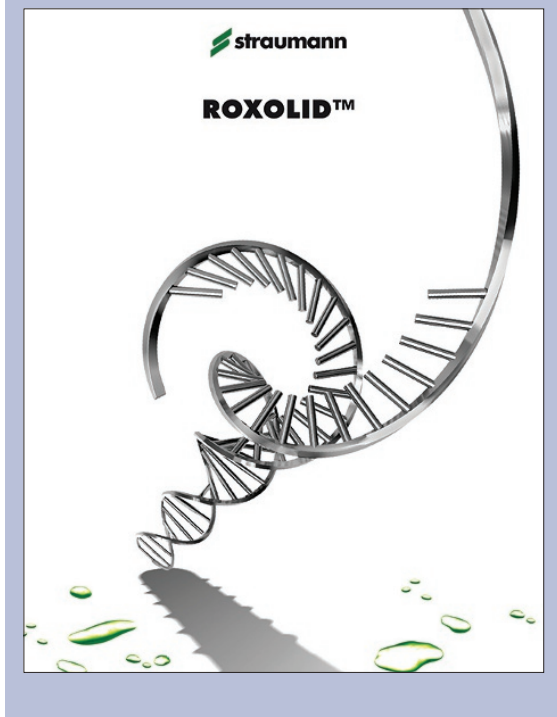

Credit will be given for identifying solutions as well as potential challenges, and for entries that are innovative and/or demonstrate an appreciation of the perspectives of all parties.

The deadline for entries is March 1st, 2010. The bursary recipients will be announced at the British Dental Association Conference and Exhibition, May 20-22 in Liverpool, UK.

Reader response number 66 